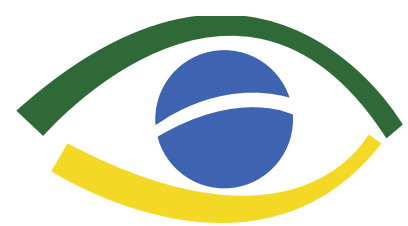

Observatório da Jurisdiçãc Constitucional
Observatório da Jurisdição Constitucional. Ano 7, no. 2, jul./dez. 2014. ISSN 1982-4564.

\title{
- Poder Executivo na construção do Direito Constitucional: uma breve análise do caso brasileiro
}

Jorge Octávio Lavocat Galvão*

Resumo: $O$ presente artigo tem como escopo analisar as intricadas relações estabelecidas entre a Jurisdição Constitucional e o Poder Executivo. Argumenta-se que a tese de que a Suprema Corte seria essencialmente um órgão contramajoritário em uma democracia não leva em consideração a constante e intensa interferência que o Poder Executivo exerce na definição de sentido da Constituição Federal, devendo ser repensada a partir desta constatação.

Palavras-chave:

Jurisdição

Constitucional;

Premissa

\begin{abstract}
This article analyzes the interrelations between judicial review and the Executive branch. It is argued that the thesis that the Supreme Court is a contramajoritarian device in a democracy does not take into consideration the continuing and intense interference of the Executive branch in the process of constitutional construction, reason why that thesis should be rethought.
\end{abstract}

Keywords. Judicial Review, Contramajoritarian Premise; Executive branch.

Contramajoritária; Poder Executivo.

* Procurador do Distrito Federal, Professor-substituto da UnB, Professor da Graduação é Pós-Graduação do IDP, Doutor em Direito Constitucional pela USP, Mestre em Direito pela NYU e Visiting Researcher pela Universidade de Yale (2012). 
1.

No âmbito do ordenamento jurídico brasileiro, o Poder Executivo assume uma série de funções expressamente previstas na Constituição Federal de 1988 como, por exemplo, o de iniciar processo legislativo de determinadas matérias (art. $61, \S 1^{\circ} \mathrm{c} / \mathrm{c}$ art. 84, III), a expedição de decretos para o fiel cumprimento da lei (art. 84, IV), exercer a direção superior da administração federal (art. 84, I), entre outras. Há, inclusive, hipótese excepcional de exercício do controle de constitucionalidade por parte do Presidente da República, consubstanciada na possibilidade de veto de projeto de lei que fira a Carta Magna (art. 66, $\S 1^{\circ}$ ).

Para além de tais atribuições expressas, a prática constitucional nos mostra que há uma série de funções implícitas conferida ao Poder Executivo na construção do significado da própria Constituição, algo que é muito pouco explorado pela doutrina. Com efeito, a partir de uma análise mais aprofundada dos casos constitucionais, é possível identificar que o Poder Executivo interfere diretamente no resultado dos julgamentos, sendo verdadeiro partícipe, ao lado do Supremo Tribunal Federal, na definição do direito constitucional pátrio. O objetivo do presente trabalho é explorar um pouco mais essa relação não muito óbvia entre o exercício das competências do Poder Executivo e o processo de densificação das normas constitucionais.

2.

O primeiro ponto que merece melhor elucidação diz respeito à legitimidade da interferência do Poder Executivo na definição dos casos constitucionais. Para as teorias que enxergam o Supremo Tribunal Federal como - guardião da Constituição a partir de seu desenho institucional contramajoritário, expressão cunhada por Alexander Bickel ${ }^{1}$, tal interferência seria ilegítima. De acordo com essa visão, o papel dos tribunais seria exatamente o de fazer um contrapeso às decisões políticas majoritárias, o que exigiria certo distanciamento dos demais atores institucionais do Estado, especialmente do Poder Executivo. Sob esse viés, o distanciamento/imunização da política seria medida necessária para que os juízes atuassem com independência ao julgar casos que contrariem os interesses dos políticos e, especialmente, do Governo. A legitimidade da jurisdição constitucional - enquanto órgão composto de juízes não eleitos que eventualmente invalida decisões tomadas por representantes escolhidos pelo povo - residiria, portanto, nesta capacidade das Corte de contramajoritariamente reconhecer que determinados direitos precedem e vinculam as escolhas políticas.

É nessa perspectiva que, por exemplo, Ronald Dworkin classifica a Suprema Corte estadunidense como um fórum de princípios, no qual os direitos

\footnotetext{
${ }^{1}$ BICKEL, Alexander. The Least Dangerous Branch: the Supreme Court at the Bar of Politics. New Haven: Yale University Press, $2^{\text {a }}$ ed., 1986.
} 
fundamentais serviriam como trunfos contra as maiorias ${ }^{2}$. Como, então, nesse contexto, reconhecer que o Poder Executivo influencia na definição do conteúdo da Constituição Federal e, consequentemente, na definição e reconhecimento dos próprios direitos fundamentais? Em outras palavras, não seria contraditório afirmar que o Poder Executivo teria capacidade de interferir no processo de interpretação constitucional, sendo que o objeto de várias das decisões constitucionais seria exatamente o de reconhecer direitos contra a maioria representada pelo Poder Executivo?

Se no campo teórico o insulamento da Corte Constitucional é muitas vezes festejado como um mecanismo de descolamento dos juízes do ambiente de barganhas da política - o que lhe daria a imparcialidade necessária para vencer o determinismo social e impor uma agenda jurídica progressista -, o que se verifica na prática é que os tribunais estão inseridos dentro da engrenagem política, influenciando e sendo influenciados por outros atores institucionais. Assim, ainda que se possa defender que haja uma diferença entre a lógica preponderante na política e no direito ${ }^{3}$, o fato é que tanto as cortes como os demais órgãos representativos exercem parcela do poder político estatal, havendo uma intrincada rede de inter-relações entre os Poderes que não vem sendo devidamente explorada pelas tradicionais teorias constitucionais que romantizam o papel das Cortes na proteção dos direitos fundamentais.

Partindo exatamente da constatação de que a Suprema Corte norteamericana exerce poder político, Robert Dahl ${ }^{4}$, em artigo publicado nos idos de 1956, após realizar uma extensa análise dos casos em que a Corte havia declarado a inconstitucionalidade de leis federais, chegou a algumas conclusões que invalidam, de certa maneira, a crença no papel contramajoritário dos tribunais, quais sejam: i) a principal função da Corte é legitimar as políticas públicas adotadas pelos governantes, já que as suas decisões normalmente estão alinhadas com as preferências da maioria política no poder; e (ii) a Corte pode eventualmente estabelecer políticas públicas sobre temas que não possuam o apoio de uma coalizão política estável, desde que haja relativo consenso dos líderes políticos sobre o teor da medida, citando como exemplo o caso Brown $v$. Board of Education ${ }^{5}$, decisão em que se ordenou o fim das políticas de segregação racial nas escolas públicas norte-americanas.

Ou seja, Robert Dahl constatou que, ordinariamente, a Suprema Corte age de maneira convergente com as posições das lideranças políticas federais. Assim, a melhor imagem dos juízes constitucionais não seria a de um árbitro, que

\footnotetext{
${ }^{2}$ DWORKIN, Ronald. The Forum of Principle. New York Law Review, vol. 56, nº. 2, p. 469-518, 1981.

${ }^{3}$ Para uma defesa da existência de uma lógica jurídica própria, cf. GALVÃO, Jorge. O Neoconstitucionalismo e o fim do Estado de Direito. São Paulo: Saraiva, 2014.

${ }^{4}$ DAHL, Robert. Decision-Making in a Democracy: The Supreme Court as a National Policy-Maker. Journal of Public Law, n. 6, p. 279-295, 1957.

${ }^{5}$ Brown v. Board of Education, 347 U.S. 483 (1954)
} 
analisa eventuais transgressões das normas por parte dos demais atores políticos, mas a de verdadeiro parceiro, que auxilia na concretização de determinadas políticas públicas, legitimando-as sob a linguagem do direito constitucional. O caráter aberto das principais cláusulas constitucionais, mormente aquelas que estabelecem direitos fundamentais, torna possível que a Corte amolde a sua interpretação às exigências político-sociais circunstanciais. $\mathrm{Na}$ jurisprudência norte-americana, por exemplo, a atualidade do pensamento de Dahl fica evidente no voto do Chief Justice John Roberts pela constitucionalidade dos principais pontos do Affordable Care Act, ou "Obama Care": um Justice de notórios laços republicanos cujo voto manteve em pé uma das mais importantes políticas públicas do Governo democrata ${ }^{6}$.

Percebe-se, pois, que o processo de significação do direito constitucional envolve muito mais do que meras interpretações jurídicas do texto constitucional, mas depende da interação dos diversos atores políticos na transformação de questões políticas em casos constitucionais relevantes. Ou seja, o direito constitucional não se apresenta como um conjunto de regras estanques, que são aplicadas rigidamente por juízes, mas como um projeto em evolução, que se adequa às necessidades de cada geração, a partir de uma interlocução entre os diversos atores políticos e a Corte. É por tal razão que alguns constitucionalistas norte-americanos buscaram compreender e destacar o papel do Poder Executivo nesse processo.

3.

O Professor Bruce Ackerman, da Universidade de Yale, em sua obra "Nós, o Povo Soberano" ${ }^{\prime 7}$, tenta, a partir do ferramental da Ciência Política, identificar o processo cíclico de ressignificação do texto constitucional norte-americano ao longo de sua história. A tese defendida pelo referido autor é a de que existiria, nos Estados Unidos, uma democracia dualista: em hipóteses de extraordinária comoção política, o povo norte-americano iniciaria um processo político de redefinição de sua identidade constitucional, configurando o que o autor denomina de momento constitucional, já na maior parte do tempo, as decisões coletivas são tomadas pelos representantes democraticamente eleitos, por meio do que o autor denomina de política ordinária, sem que haja a participação direta dos cidadãos. A democracia dualista, portanto, se caracterizaria pela ocorrência, ao longo da história, de alguns momentos de política extraordinária que redefiniriam as bases para o exercício da política ordinária. Nesse sentido, o papel da Suprema Corte seria o de preservar os compromissos assumidos pelo povo nos momentos constitucionais, impedindo que a política ordinária os subverta.

\footnotetext{
${ }^{6}$ National Federation of Independent Business v. Sebelius, 567 U.S. (2012)

${ }^{7}$ ACKERMAN, Bruce. Nós, o Povo Soberano: Fundamentos do Direito Constitucional. Belo Horizonte: Del Rey, 2006.
} 
Ocorre que, no pensamento de Ackerman, nem todo momento constitucional insere uma emenda formal à Constituição. É possível que o novo compromisso constitucional afirmado pelo povo modifique a compreensão dos próprios cidadãos, inclusive dos juízes, sobre o sentido de determinadas cláusulas constitucionais, sem que haja a alteração do texto constitucional. Assim, ainda que não haja qualquer emenda constitucional propriamente dita, o autor afirma ser possível verificar, a partir das decisões prolatadas pela Suprema Corte, que houve uma mudança constitucional. Para corroborar o seu entendimento, o autor afirma que a política do New Deal, implementada pelo Presidente Roosevelt na década de 30, configurou-se verdadeiro momento constitucional, o que pôde ser percebido pela guinada jurisprudencial da Suprema Corte, que abandonou as teses do laissez-faire de outrora e acabou chancelando políticas estatais intervencionistas.

Para facilitar a identificação desses chamados momentos constitucionais, Ackerman cataloga a sequência de fatos que os antecedem: segundo o autor, ordinariamente há diversas reivindicações em ebulição na sociedade contra a ordem política vigente, sendo que a maioria delas não sucedem na arena política. Os casos bem sucedidos normalmente dependem do endosso pelo Presidente da República, que passa a defender abertamente determinada demanda política como, por exemplo, o fim da segregação racial -, sendo apoiado por seu partido político. Ademais, para que a demanda se torne foco de uma política extraordinária, é necessário que a população se engaje no debate sobre o tema, o que normalmente ocorre nas eleições presidenciais subsequentes, nas quais a questão se torna um dos principais pontos de divergência entre os candidatos concorrentes. Caso o partido do proponente sagre-se vencedor em sucessivas eleições e o partido oponente não mais rejeite tal bandeira política, mas apenas questione o seu significado futuro, então a Suprema Corte acaba por legitimá-la na linguagem do direito constitucional. Para Ackerman, o estabelecimento de uma maioria convergente nos três poderes é um indício de que ocorreu uma transformação no sentido da Carta Magna ${ }^{8}$.

Vê-se que, para o autor, o resultado dos casos constitucionais está intimamente ligado ao processo político no qual o caso foi gerido, sendo o Poder Executivo um dos principais, senão o principal, ator institucional a deflagrar a ressignificação das cláusulas constitucionais a partir do endosso de lutas políticas relevantes. Ackerman, contudo, ainda trabalha tentando estabelecer conexões abstratas entre a relação dos poderes e eventual mudança constitucional, sem especificar quais mecanismos concretos levam a essa interlocução entre o Poder Executivo e o Judiciário.

Jack Balkin, outro constitucionalista da Universidade de Yale, tem como escopo diagnosticar essas pontes institucionais entre a política e o direito constitucional $^{9}$. Balkin sustenta que as interpretações constitucionais levadas a

\footnotetext{
${ }^{8}$ Cf., também, ACKERMAN, Bruce. The Living Constitution. Harvard L. Rev. nº. 126, 2006-2007, p. 1738.

${ }^{9}$ BALKIN, Jack. Living Originalism. Cambridge: Harvard University Press, 2011.
} 
cabo pelas Cortes não podem ser consideradas como as únicas interpretações legítimas da Constituição, sendo, na verdade, fruto de um processo maior de construção constitucional, que ocorre a todo instante na comunidade política. As leis aprovadas pelo Congresso e os decretos editados pelo Poder Executivo, por exemplo, são construções constitucionais, na medida em que são aplicações de determinadas competências constitucionais, formando uma rede interligada de decisões que, no todo, moldam a nossa compreensão sobre a Constituição Federal. O direito constitucional, portanto, é o resultado dessa interação dinâmica de construção constitucional, havendo uma relação de causalidade entre os atos de diversos atores institucionais e os resultados jurisprudenciais dos casos constitucionais relevantes.

A tese de Balkin, quando comparada à de Ackerman, é mais realista ao perceber que mudanças de orientação jurisprudencial estão intimamente ligadas ao perfil das indicações dos juízes pelos Presidentes e à pressão exercida sobre a Corte em determinados casos. Com relação ao primeiro ponto, o autor afirma que o Poder Executivo tende a escolher magistrados que se aproximem de suas pré-compreensões de mundo, de maneira que seu legado acaba se perpetuando para além do mandato presidencial, já que os juízes normalmente permanecem no cargo por vários anos após sua indicação. Já o segundo ponto salienta quanto a Corte é permeável a pressões de determinados atores políticos. Sustenta, assim, que determinadas bandeiras políticas endossadas pelo Poder Executivo, por partidos políticos ou por movimentos sociais influentes têm mais chances de serem transformadas em direito constitucional do que se arguidas por outros agentes. É nesse contexto que Balkin lança mão dos conceitos on-the-wall e offthe-wall, concernentes à capacidade de um agente, como o Poder Executivo, colocar, ou não, um caso na agenda da Suprema Corte. Caso seja bem sucedido em transformar uma questão meramente política em um caso constitucional apreciado pela Corte, diz-se que a questão está on-the-wall.

A partir das premissas de Balkin, é possível concluir que o direito constitucional está em constante mutação, sendo que o Presidente da República possui mais chances de ver transformar suas convicções políticas em direito constitucional quanto maior for a pressão social exercida sobre a Corte e quanto maior for o número de juízes por ele indicados. A partir de tais constatações no âmbito do direito constitucional norte-americano, é possível perceber alguns elementos na prática constitucional brasileira que parecem indicar essa mesma interação institucional em nosso contexto.

\section{4.}

Não há dúvidas de que o direito constitucional brasileiro vivenciou na última década uma profunda transformação: o protagonismo atual do Supremo Tribunal Federal é fruto de uma mudança de compreensão sobre o papel da Corte na democracia brasileira. Coincidentemente, este período marca a ascensão do Partido dos Trabalhadores ao Poder Federal. Seria possível traçar um paralelo 
entre a mudança do perfil da Corte e a orientação programática do partido governista?

No Brasil, diferentemente dos Estados Unidos, não há uma distinção clara entre juízes liberais e conservadores, o que dificulta a análise. É possível, contudo, verificar algumas evidências. O Partido dos Trabalhadores historicamente assumiu uma postura política de promoção dos direitos de minorias, como direitos dos indígenas, de gênero e de igualdade raça. Ao longo do governo petista, por exemplo, foram criadas a Secretaria de Políticas para as Mulheres e a Secretaria de Políticas de Promoção da Igualdade Racial. Nesse mesmo período, houve um incremento na jurisprudência sobre esses temas, que passaram a integrar a agenda da Corte. Assim, pode-se inferir que o julgamento de alguns casos constitucionais relevantes não tenha sido mera obra do acaso, mas fruto de um processo político mais amplo, podendo ser citados, como casos relevantes, a PET $n^{\circ} .3 .388$ (Raposa Serra do Sol), a ADPF $n^{\circ} .54$ (aborto de fetos anencefálicos), a ADPF $n^{\circ} .132$ (casamento homo afetivo) e a ADPF no. 186 (cotas raciais na UnB).

A própria doutrina constitucional parece ter sido afetada pela agenda política do partido governista. Com efeito, é fato notório que uma das diretrizes econômicas mais relevantes dos governos petistas relaciona-se à redistribuição de renda, seja por meio de programas sociais e por meio do aumento real do salário mínimo. No contexto, a ascensão da chamada doutrina neoconstitucional, endossada expressamente por alguns ministros, não se apresenta como algo acidental: os autores neoconstitucionalistas brasileiros pregam 0 uso instrumental do direito constitucional para a promoção de justiça social ${ }^{10}$. Ou seja, há uma identidade de agendas que não pode ser menosprezada.

É importante salientar, ademais, que não só as indicações para o cargo do ministro do STF parecem ser relevantes para o amoldamento do direito constitucional. No caso brasileiro, o Advogado-Geral da União e o ProcuradorGeral da República participam ativamente na jurisdição constitucional (art. 103, §§ $1^{\circ}$ e $3^{\circ}$, da CF/88), de maneira que o perfil de atuação dos indicados para estes cargos acaba influenciando no resultado final dos casos. Cite-se, como exemplo, a ADI n. 3.082, de relatoria do Min. Sepúlveda Pertence, na qual se questionava instrução normativa do TST que obstava a inscrição de portadores de deficiência física em concurso público, quando estes necessitassem, para fazer a prova, de intermediários permanentes. O então Advogado- Geral da União ao invés de defender a constitucionalidade do ato, que seria o seu múnus constitucional, sustentou que norma violaria os princípios da igualdade e da dignidade, requerendo a procedência da ação.

Já no caso da ADPF $\mathrm{n}^{\circ}$. 165, na qual se discute a constitucionalidade dos planos econômicos das décadas de 80 e 90, é notória a influência do AdvogadoGeral da União, que busca postergar o julgamento do caso para minimizar os

\footnotetext{
${ }^{10}$ Explico-me melhor nos capítulos 2 a 4 do livro GALVÃO, Jorge. O Neoconstitucionalismo e o fim do Estado de Direito. São Paulo: Saraiva, 2014.
} 
eventuais prejuízos que os bancos, incluídos os bancos públicos, terão caso a ação seja julgada favoravelmente aos poupadores. Nesse caso específico, o Poder Executivo age no intuito de retirar o caso da agenda da Corte, para colocá-lo offthe-wall, na feliz expressão de Jack Balkin, tendo sido bem sucedido até o momento.

Por outro lado, um caso marcante, que demonstra a permeabilidade da Corte à pressão exercida por determinados atores políticos, que conseguem colocar alguns temas on-the-wall, pode ser verificada na ADI no. 4.467, ajuizada às vésperas das eleições gerais de 2010 pelo Partido dos Trabalhadores, que questionava a razoabilidade da exigência legal de dupla identificação do eleitor. Não obstante o seu extenso estoque de processos, o Supremo Tribunal Federal, em menos de 5 dias, decidiu em Plenário pela concessão de medida cautelar, afastando tal exigência para o pleito que seria realizado em menos 15 dias.

Adverte-se que tais considerações não devem ser entendidas como críticas à atuação do Supremo Tribunal Federal. Tais apontamentos apenas revelam o óbvio: há uma intensa troca de experiências entre a Corte e demais atores institucionais. A convergência de agendas não revela uma subversão da jurisdição constitucional, mas que há um processo de aprendizagem e convencimento mútuo entre a política e o Poder Judiciário. Assim, os juízes não chegam a tais conclusões por má-fé ou porque foram corrompidos, mas por concluírem que tais interpretações constitucionais são as melhores possíveis diante de determinado contexto político-social. E os dados que subsidiam tal conclusão são em grande parte produzidos por agentes políticos que agem em nome Poder Executivo, que obviamente tem interesse no caso.

5.

Tais observações indicam uma intensa comunicação entre o Poder Executivo e a jurisdição constitucional que merece ser, ao invés de escamoteada, mais bem trabalhada pelos doutrinadores, que devem: i) ou teorizar sobre a legitimidade da Corte sob esse viés de interferência dos órgãos majoritários; ii) ou sugerir alternativas institucionais para minimizar tal interferência, ressaltando o seu papel contramajoritário.

\section{Referências Bibliográficas}

ACKERMAN, Bruce. Nós, o Povo Soberano: Fundamentos do Direito Constitucional. Belo Horizonte: Del Rey, 2006.

. The Living Constitution. Harvard L. Rev. n. 126, 2006-2007, pp. 1737-1812. 
BALKIN, Jack. Living Originalism. Cambridge: Harvard University Press, 2011.

BICKEL, Alexander. The Least Dangerous Branch: the Supreme Court at the Bar of Politics. New Haven: Yale University Press, $2^{\mathrm{a}}$ ed., 1986.

DAHL, Robert. Decision-Making in a Democracy: The Supreme Court as a National PolicyMaker. Journal of Public Law, n. 6, p. 279-295, 1957.

DWORKIN, Ronald. The Forum of Principle. New York Law Review, vol. 56, n. 2, 1981, pp. 469-518.

GALVÃO, Jorge. O Neoconstitucionalismo e o fim do Estado de Direito. São Paulo: Saraiva, 2014.

\section{Legislação e Jurisprudência}

ESTADOS UNIDOS. SUPREMA CORTE. Brown v. Board of Education, 347 U.S. 483 (1954).

ESTADOS UNIDOS. SUPREMA CORTE. National Federation of Independent Business $v$. Sebelius, 567 U.S. (2012).

DOI: $10.11117 / 1982-4564.07 .14$ 